American Journal of Pharmaceutical Education 2017; 81 (9) Article 6832.

\title{
COMMENTARY
}

\section{Reflection Is Not Reflexive}

\author{
Alicia S. Bouldin, $\mathrm{RPh}, \mathrm{PhD}^{\mathrm{a}, \mathrm{b}}$ \\ ${ }^{a}$ The University of Mississippi School of Pharmacy. University, Mississippi \\ ${ }^{\mathrm{b}}$ Editorial Board Member, American Journal of Pharmaceutical Education, Alexandria, Virginia
}

Submitted October 3, 2017; accepted November 22, 2017; published November 2017.

Keywords: reflection, self-awareness, critical thinking, learning portfolios, motivation

Reflection. We have heard its value proclaimed, and have likely experienced its value in our own practice and in the development of the learners whose journey we shepherd in our schools and colleges of pharmacy. In fact, it is so frequently mentioned in the literature of professions education, that incorporation of reflection in our programs seems a given. (Articles in this Journal by Plaza and colleagues ${ }^{1}$ and Tsingos and colleagues ${ }^{2}$ provide excellent bibliographies filled with such mentions.) Reflection has been used in the education of professionals to enhance learning in contexts such as service learning, ${ }^{3}$ practice experiences, ${ }^{4}$ and co-curricular professional development (professionalism, ${ }^{5}$ self-awareness, ${ }^{6}$ collaboration, ${ }^{7}$ etc.), to name just a few applications. Reflection was purportedly cited by Confucius as the noblest method by which we gain wisdom. ${ }^{8}$ There seems to be no question that it is essential to achievement of our potential, as learners, as teachers, as professionals.

However, reflection is not reflexive or instinctive for many. Nor is it one's "second nature," automatically habit-driven and self-motivated. Reflection can be challenging, at least at first. Consequently, there are likely to be large numbers of pharmacy educators (myself included) who have experienced some student resistance to the activity.

What gets in the way of reflection? Dictionary synonyms for the word "reflection" include "contemplation, deliberation, musing" and more. In reading these words, one can intuit that time is one of the key resources required to engaging in and developing a habit of reflection, either as learning or as a tool to optimize one's professional practice. How many of us as educators neglect to write down what worked and what didn't in our conduct of a recent classroom period, laboratory session, or group facilitation, along with ideas for making the next cycle better? Many of us may carve out time to assemble such reflective data in

Corresponding Author: Alicia S. Bouldin, The University of Mississippi School of Pharmacy, 209 Faser Hall, University, MS 38677-1848. Tel: 662-915-7262.E-mail: abouldin@olemiss. edu our teaching portfolio; but just as many (perhaps more?) may have good intentions, but are inclined to relegate reflection to a quick mental review, assigning any available time to more pressing tasks - and there are many. Our students experience similar balancing acts in their apportioning of available moments.

Because time is limited, learners may perceive activities with high thought (and/or writing) quotient and low credit return as "busy work." Points are currency, and in the learning economy, students tend to value activities that earn them the most bang for their buck, despite the fact that some of the lower-point activities may in fact be high-yield investments in their personal and professional development. Those abstractions are harder to quantify than the more objective evaluations of knowledge or skills.

Reflection requires independent critical thought, an activity that demands another resource - mental energy. As more habits of mind and attitudinal components of learning are being emphasized in the curricula and cocurricula of professional education, reflection is receiving more attention, and is perhaps being incorporated more than in previous education cycles. Thus "reflection fatigue" may be a real barrier to optimal use of this learning tool. ${ }^{9}$ How much of this good thing becomes "too much?"

Distraction forms another barrier to reflection. Experience demonstrates that today's $21^{\text {st }}$ century learner is bombarded with information from all sides, and at all hours. Even at the dinner table, historically the territory of spirited engagement with conversation partners or a quiet recollection of the day's events, new information rushes to the individual on the screen of his or her smartphone or other personal device. In the spirit of constant connection, those data are taken in on top of any other activity. There is little opportunity for solitude with one's thoughts, unless that solitude is deliberately won from the competing stimuli.

One could point to another difficulty in student investment in reflective activities. Depending upon the 


\section{American Journal of Pharmaceutical Education 2017; 81 (9) Article 6832.}

structure of the experience, reflective activities may call attention to one's "opportunities for improvement," or learning/performance gaps. That may need to be framed in a fashion other than critical. Developing a discrepancy between "where I am" and "where I should be" can seem an affront to some with already fragile self-efficacy. While perhaps an over-generalization, sources suggest that millennials as a group seem to have more challenges with self-regulation and self-efficacy, perhaps more than those coming before them. ${ }^{10}$ (The positive side of this coin is that these very reflective exercises - if undertaken sincerely - might strengthen learner self-efficacy and foster a growth mindset.)

All of the above challenges - while not an exhaustive list - affect motivation to engage with learning-related reflection in a meaningful way. Despite the challenges, we routinely ask learners to engage in reflection. In fact, it has been recommended as a valuable tool in evaluating learner progress in CAPE 2013 Domains 3 and $4 .{ }^{11}$ Some suggest that more sincere and honest reflection, while enhancing the competency of self-awareness, also has potential to improve the resilience of student professionals. ${ }^{5}$ Thus it may be prudent to explore more strategies that can increase the potential effectiveness of this type of learning tool.

Modeling good reflective practice is an excellent place to start. As exposure to reflective practice in their studies prior to pharmacy school may have been limited, some learners may need examples of how reflection is accomplished, and the possible benefits of the activity. Thinking habits, if not second nature, can be adopted over time with practice. It has been suggested that tapping the contributions of our preceptor faculty can contribute to the development of reflective ability. ${ }^{4}$ Perhaps broad consideration should be given to preceptor development designed to reinforce their skillsets and buy-in to support student reflection.

Equally important, perhaps, is framing the activity in a longitudinal context. It may be challenging for $21^{\text {st }}$ century learners to cast a sincere self-critical eye upon their work and actions, especially in instances of low selfefficacy. Reinforcing that novice and intermediate-level learners are not expected to perform at levels of absolute proficiency gives learners permission to make mistakes, and by reflecting learn from them. Encouraging a longterm perspective ${ }^{2}$ may aid in the efficacy of the practice, and foster lifelong learning habits of mind.

How can we increase the perceived value? Beyond modeling the value to one's overall practice as a professional or student professional, the value of the activity can be enhanced in the eyes of learners if they receive what they perceive to be adequate reward for their investment of time, thought, and effort. However, as has been suggested by others, ${ }^{12}$ assessment of reflective exercises presents its own challenges. Rubrics have been deployed to objectively examine student performance on what is by its nature a relatively subjective exercise. ${ }^{12}$ But including reflection in learning portfolios is often "assessed" via a checklist (is evidence of the activity present or not). Would more weighted assessments in the context of course grades enhance the perception of "credit," and thus improve effort? Would such extrinsic motivation positively influence habits of mind for future practice? What examples of quantitative assessments of reflective exercises are being used with much success in health professions education?

How many exercises, and at what depth of reflection, are needed to foster lasting and productive habits, or to internalize the practice in a variety of settings (didactic, experiential, post-graduation, etc.)? What are some characteristics of learners who are early adopters of reflective practice? What techniques are most effective in encouraging those with less inspiration to engage in reflection? Some empirical questions related to reflection have been explored in the context of pharmacy education. ${ }^{13,14}$ If we agree that reflection is an important component to development of the whole pharmacy practitioner, continued and enhanced scholarship of assessment, learning, and teaching (SALT) in this conceptual domain may provide significant benefit - not only to individual learners and local teaching practices, but also to the practices of colleagues throughout the Academy.

\section{REFERENCES}

1. Plaza C, Draugalis JR, Slack MK, Skrepnek GH, Sauer KA. Use of reflective portfolios in health sciences education. Am J Pharm Educ. 2007;71(2):Article 34.

2. Tsingos C, Bosnic-Anticevich S, Smith L. Reflective practice and its implications for pharmacy education. Am J Pharm Educ. 2014;78(1):Article 18.

3. Schumann W, Moxley DP, Vanderwill W. Integrating service and reflection in the professional development of pharmacy students. $\mathrm{Am}$ $J$ Pharm Educ. 2004;68(2):Article 45.

4. Wallman A, Lindblad AK, Gustavsson M, Ring L. Factors associated with reflection among students after an advanced pharmacy practice experience (APPE) in Sweden. Am J Pharm Educ. 2009;73(6):Article 107.

5. Wald HS. Professional identity (trans)formation in medication education: reflection, relationship, resilience. Acad Med. 2015; 90(6):701-706.

6. Pai HC. The effect of a self-reflection and insight program on the nursing competence of nursing students: a longitudinal study. J Prof Nurs. 2015;31(5):424-431.

7. Van Winkle LJ, Cornell S, Fjortoft N, et al. Critical thinking and reflection exercises in a biochemistry course to improve prospective health professions students' attitudes toward physician-pharmacist collaboration. Am J Pharm Educ. 2013;77(8):Article 169.

8. Confucius on WikiQuote. https://en.wikiquote.org/wiki/Confucius. Accessed September 27, 2017. 


\section{American Journal of Pharmaceutical Education 2017; 81 (9) Article 6832.}

9. Trumbo SP. Reflection fatigue among medical students. Acad Med. 2017;92(4):433-434.

10. Palmer JS. "The millennials are coming!": improving selfefficacy in law students through universal design in learning. Cleveland State Law Rev. 2015;63(3):8.

11. Fulford MJ, Souza JM, Alston GL, et al. Are You CAPE-A.B.L.E? Center for the Advancement of Pharmacy Education: an assessment blueprint for learning experiences. 2015. http://www.aacp.org/ resources/education/cape/Documents/Assessment $\% 20 \mathrm{CAPE} \%$ 20Paper-\%20Final\%2011.pdf. Accessed October 2, 2017.
12. Tsingos C, Bosnic-Anticevich S, Lonie JM, Smith L. A model for assessing reflective practices in pharmacy education. Am J Pharm Educ. 2015;79(8):Article 124.

13. Austin Z, Gregory PAM, Chiu S. Use of reflection-in-action and self-assessment to promote critical thinking among pharmacy students. Am J Pharm Educ. 2008;72(3):Article 48.

14. Tsingos-Lucas C, Bosnic-Anticevich S, Schneider CR, Smith L. The effect of reflective activities on reflective thinking ability in an undergraduate pharmacy curriculum. Am J Pharm Educ. 2016;80 (4):Article 65. 